\title{
Analysis of Avedon's Photographic Works
}

\author{
He Yang \\ Huanghe Science and Technology College \\ Zhengzhou, China
}

\begin{abstract}
Richard Avedon is a famous photographer whose career was listed as "one of the professional photography models in the last century" 1 . He has been regarded as a fashion photographer, but he is not a traditional fashion photographer. He innovatively brought models outside studio to shoot, and introduced many new elements into fashion photography, such as news photography, portrait photography and even photography collage, which greatly enriched the performance of fashion photography. In addition, he also cared about the progress of the society and human development. He shot a lot of outstanding portrait photographs in special shooting way. He went to the grassroots of the American West to shoot, and gave portrait photography a deeper meaning.
\end{abstract}

\section{Keywords-fashion; portrait; photography}

\section{INTRODUCTION}

Richard Avedon (1923 2004), American, was born on May 15, 1923, in New York. His father has ever opened a women goods shop on the Fifth Avenue of New York City, which gave Richard Avedon chance to contact with all kinds of fashion ads and related ads. This has a subtle influence on his future career.

Richard Avedon studied in a public school in New York City and graduated from Columbia University. After graduation, he began to learn photography, and found a job in the camera crew of Bureau of Shipping.

At the age of 21 he learnt after Aexey Brodovitch, art director of Harper Market, and first took a photo for this newspaper. In 1946, he set up the Photographic Studio of Richard Avedon, and became the press photographer of Harper Market, Art Stage and Vogue. After the World War II in the 20th Century, his photographic works became popular in fashion photography circle. He and another American photographer Irving Penn took the leading position in Western fashion photography circle for more than 20 years.

\section{DOVIMA WITH ELEPHANTS IN 1955}

Dovima and Elephants (Fig.1) is a collection of black and white photos. Richard Avedon took these photos for Dior's evening dress in 1995. These photos were a great success, and established his place in fashion photography.

\footnotetext{
1 Avedon's occupation career was listed as "one of the professional photography models in the last century" by Susan Santa Gregory.
}

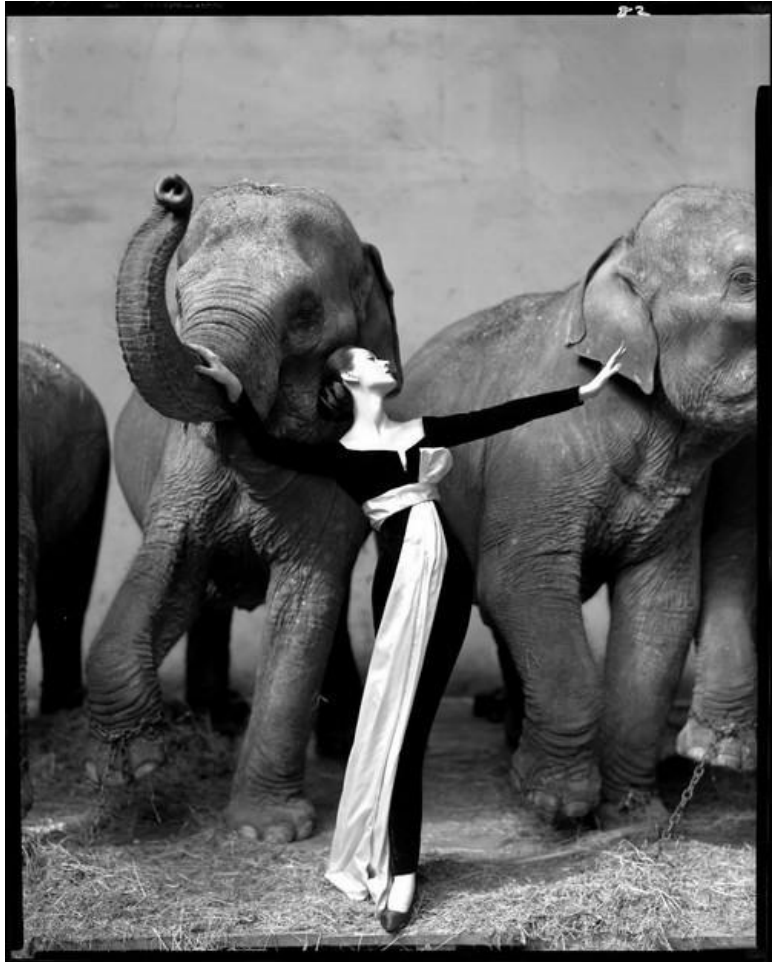

Fig. 1. Richard Avedon's Dovima and Elephants in 1955

Whimsical Richard Avedon brought the model to the circus and shot photos before elephants. The model wore a silk evening dress. The feminine and fashionable model formed a sharp contrast with elephants' rough skin and clumsy image, which gives people a great visual impact. The curly long nose of elephants contrasted finely with the graceful posture and bent arms and the floating ribbon of the model. However, is it Richard Avedon's purpose to show these aspects? To show fashion? Of course not, behind the fashion hid a deeper meaning - suffering, "universal suffering of mankind"2.

\section{OBSERVATIONS IN 1959}

Richard Avedon used palatial picture and lavishly dressed women to express a golden and super good life myth. With his insight on the characteristics of various genres, and deep understanding on the great power of contemporary mass media, Richard Avedon quickly became the most famous and first-

${ }^{2}$ Richard Avedon: "sometimes I think, I shoot photos only related to myself What I concern is ... universal suffering of mankind, and the suffering I care about in a sense is myself". 
class photographer of Vogue. However, Richard Avedon, as a fashion photographer, didn't recognize his position. He thought it just gave him a channel to capture celebrities.

In 1959, Richard Avedon published his first book Observations. In this book, many celebrities appear in front of his camera, showing the good relations and attraction between them. Most of them, unlike fashion models, were celebrities in society, which gives Richard Avedon's photographic works with special meaning...

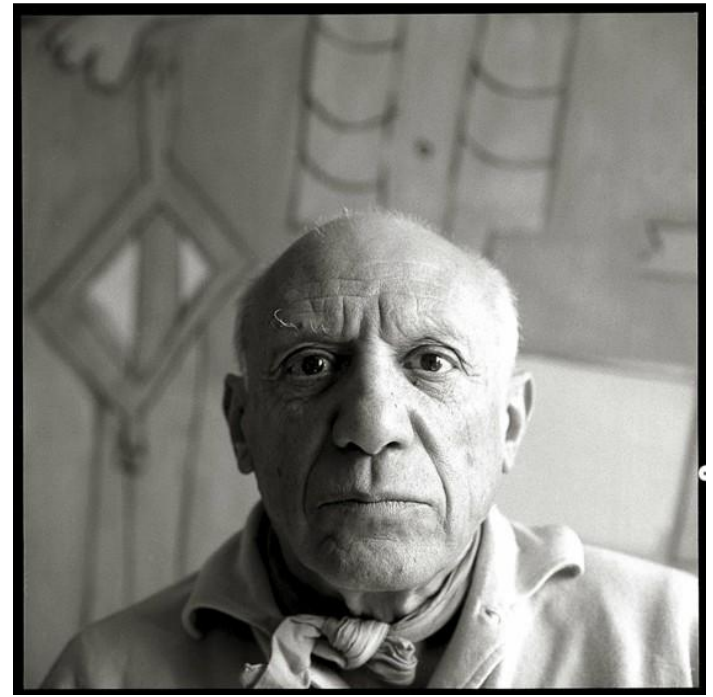

Fig. 2. Richard Avedon's Pablo Ruiz Picasso in 1958

Richard Avedon took this portrait works (Fig.2) for Pablo Ruiz Picasso. In this picture, Picasso was placed in the lower part, which makes the image more close to viewer. The bur cubism paintings of depth-of-field effect behind him express his identity as an artist. This specific environment related to reality was gradually weakened in the later portrait works of Richard Avedon. The use of side lights deeply portrays facial wrinkles and locked eyebrows of the figure, which clearly shows the inner world of the figure behind the camera.

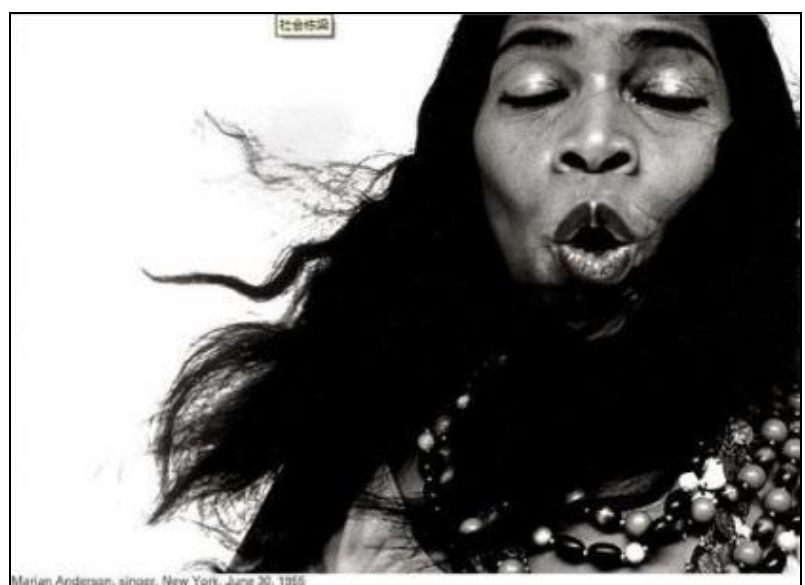

Fig. 3. Richard Avedon's Marian Anderson in 1959
The portrait of Marian Anderson ${ }^{3}$ is of another style. This portrait photo adopted "his wants, a white background" 4 , which makes the figure more prominent. The side lights at the top and the right-most placement of figure form a typical balanced composition with floating black hair. The closed eyes and skilled lips ${ }^{5}$ and floating hair seem that we can feel a gust of low sounds of nature.

These photos successfully blend types of fashion together. It gradually broke the boundary of fashion, and led a new but disturbing political image.

\section{NOTHING PERSONAL IN 1964}

Nothing Personal was published in 1964. It was Richard Avedon's second book. He tried to introduce some historical moments in this book. Even these photos were arranged in a narrative way, but they were still like isolated portraits, which forcefully suggested the sense of alienation in 1960s.

All shooting people were arranged as a meaningful symbol. Each photo is turned into an appeal of thought. It guides us to see the society from certain angle rather than from certain value. This book provides us a disturbing arrangement of sad, bitter, flattered and ruthless pictures. Like the group of portraits in "Daughters of the American Revolution" (Fig.4), it imitated Twelve World Top Models published by Irving Penn ${ }^{6}$ in 1974. It is like an irony to a family of arrogance.

In this book there is a vivid and profound photo of a historical figure, William Casspi, a Negro slave (Fig. 5). The face of the figure is almost full of the picture. The use of top lights casts many heavy shadows on the face of the figure, which vividly shows the sadness, anger and pain of Casspi and reflects his miserable life experience.

Nothing Personal undoubtedly attracted the attention of the people. This book presents such a distinct purpose: on the overall conception, he will not be fragmented by capricious and puzzling theme. The arrangement of all photos and euphuism among portraits are cut. They are isolated by the background cloth behind them, and it limits their body language in a non-original state. The shooting people always hope their portrait looks more individual. However, Richard Avedon transformed the personality of model into an aura, and brought their portrait photographs into a new and dramatic field by professional means.

\footnotetext{
3 Afro American Alto

${ }^{4}$ Richard Avedon: "I start from a series of 'not wants', no delicate lighting, no surface composition and no posture or narrative. And these 'not wants' force me to 'wants', white background, people interested in, and things happened among us".

${ }^{5}$ The shooting people are cut into a pattern by his specific image production, so you can see Marian Anderson's skilled lips.

${ }^{6}$ Famous American Photographer
} 


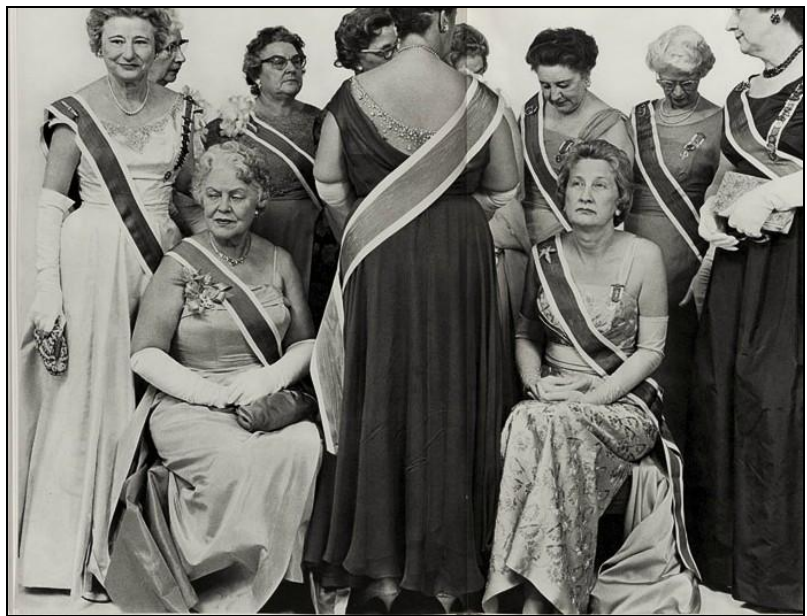

Fig. 4. Richard Avedon's Daughters of the American Revolution

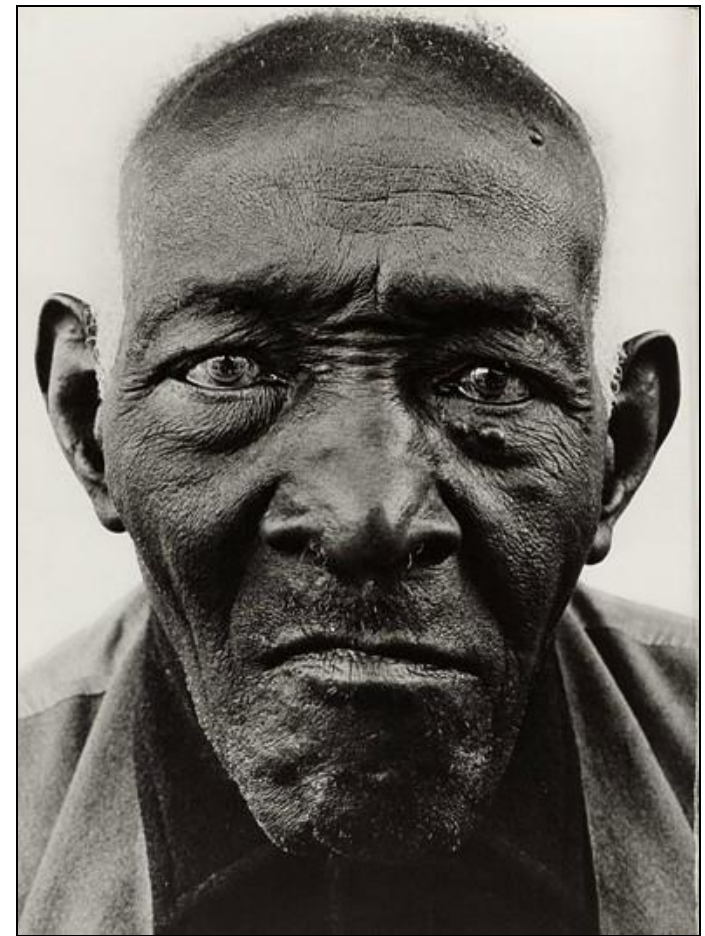

Fig. 5. Richard Avedon's William Casspi

Richard Avedon never ordered about models rudely or hidden physical defects of the shooting people. In his camera, people were stripped off the masks in daily life, and were forced to present in their true self which often surprised us. In photos of Richard Avedon, the presentation things people displayed are so few, so they become more rich and abundant. Nothing Personal foresaw Richard Avedon's creation route. In 1976, Avedon published Portraits. The shooting people in this book, seen from actual space, are very close to the shot which completed removed the emotional surface of the shooting person.

\section{PORTRAITS IN 1976}

In Richard Avedon's photographic works, we cannot see similes on the faces of the shooting people in a long period. These people did have smiles in their life, but they deliberately hid their smiles before posing for shoot or in the moment the photographer pressed the shutter.

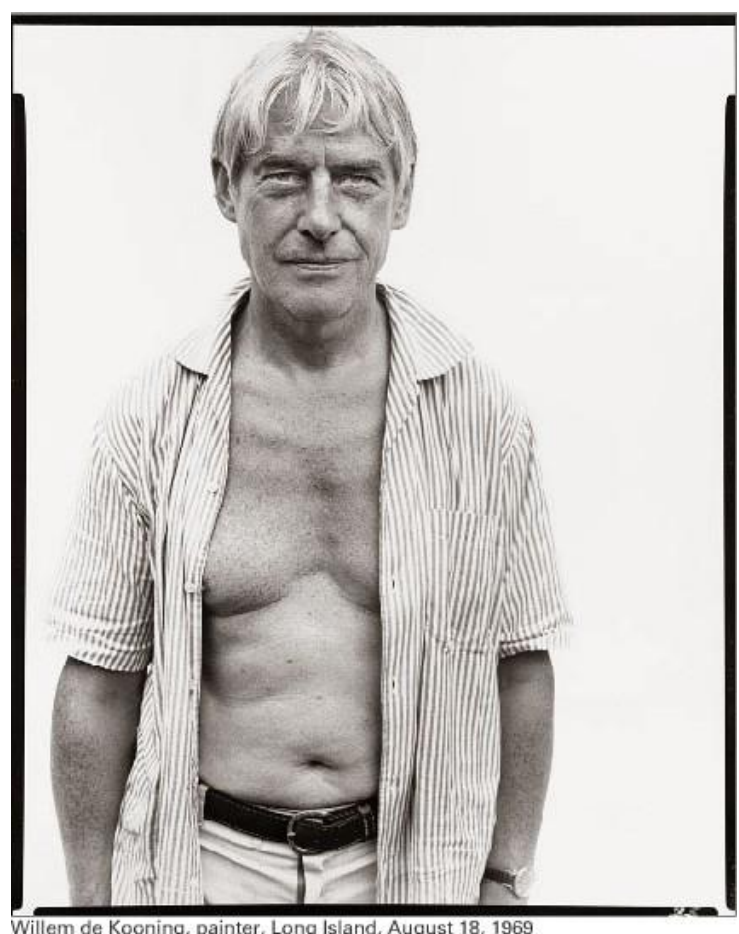

Fig. 6. Richard Avedon's Willem de Kooning in 1969

As Richard Avedon's shooting person, Willem de Kooning $^{7}$ (Fig.6) described Richard Avedon's shooting to Harold Rosenberg": "Richard captured the photo as he asked me: 'why don't you smile?' I smiled, but before it he had already finished..."

De Kooning's photo and the description were collected in Richard Avedon's Portraits, a photographic collection of portraits of celebrities in arts and communication circles. This portrait collection is full of "inopportune" snap shots. The shooting people often wore a dull, tired expression, even an expression as if they were going to die (Fig.7 \& Fig.8). He even took a photo (Fig.8) of American pop art advocator and leader Andy Warhol ${ }^{9}$ after his assassination with side lights. This is a close-up of the upper body. Several crooked long scars interwoven together, which is dreadful. This photo has become one of his most famous photos.

At the end of the book, a group of photos of "noncelebrities" were shot in the period from 1969 to 1972. These photos are photos of his father Jacob fighting cancer (Fig.9). They were shot in a narrative way. On the white background the body condition of Jacob gradually became weak under the

\footnotetext{
${ }^{7}$ The outstanding representative of abstract expressionism

${ }^{8}$ American writer, educator, philosopher and art critic

${ }^{9}$ One of the most famous figures in the art world in 20th Century, advocator and leader of the pop art
} 
torture of disease, and until he died. However, this is not just a simple record of a life to death, but rather a manifestation of Jacob's horror of his decaying body. This horror gave the best footnote to the Portrait.

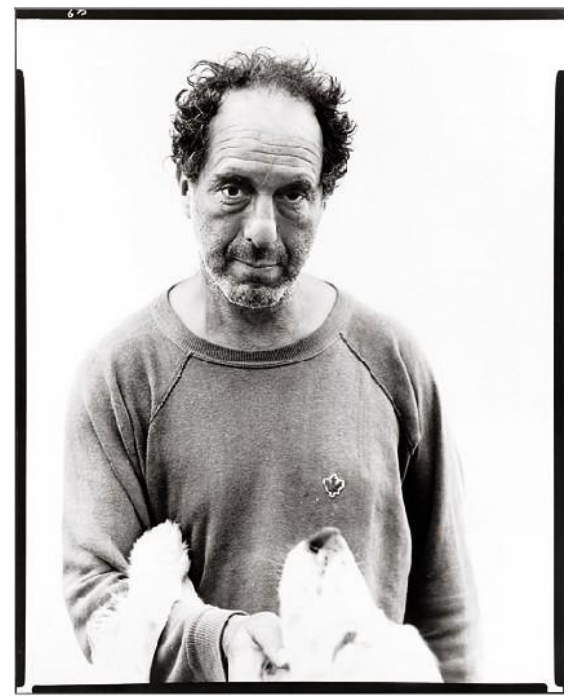

Fig. 7. Richard Avedon's Robert Frank ${ }^{10}$ in 1975

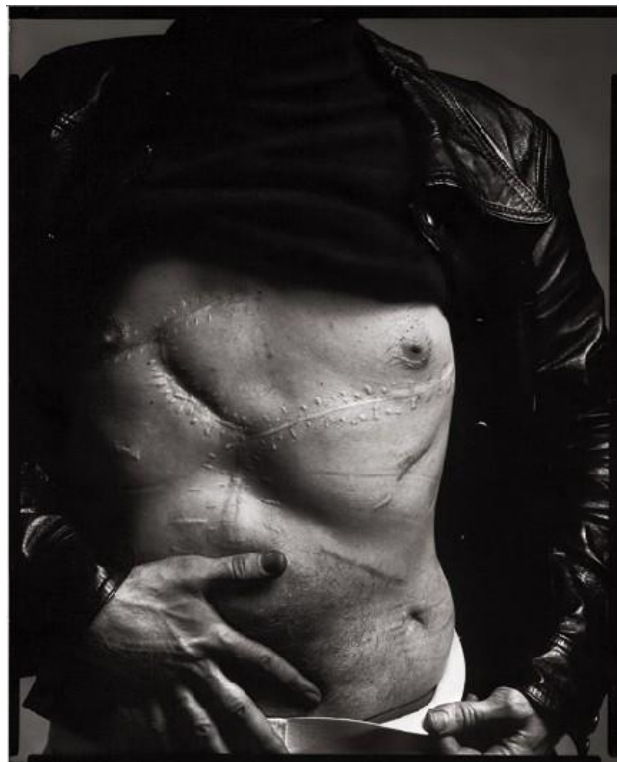

Fig. 8. Richard Avedon's Andy Warhol in 1969

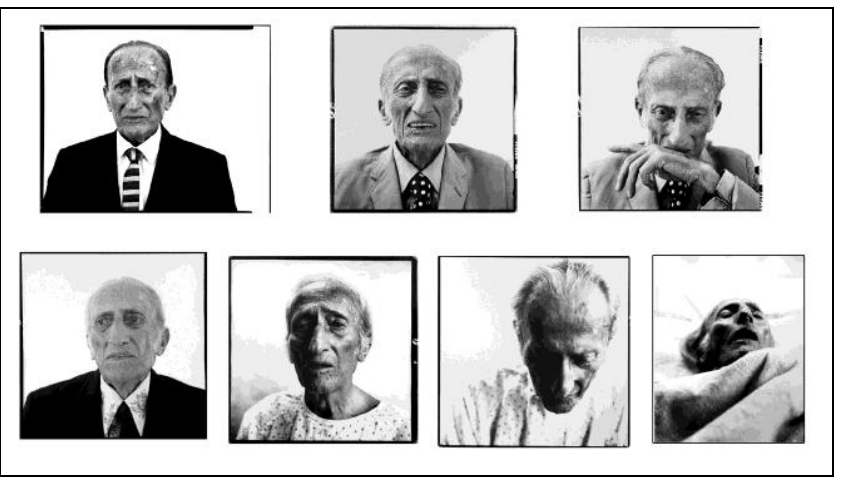

Fig. 9. Richard Avedon's Jacob Israel Avedon from 1969 to 1972

\section{IN THE AMERICAN WEST IN 1985}

Richard Avedon was a master of fashion photography, but he cared not just about fashion and celebrities. From 1979, he went to 17 states in the American West for five consecutive years and shot for workers, farmers, drivers, prisoners, vagrants, etc. in coal mines, oil fields, pastures, hospitals, prisons and so on. In 1985 he published the photographic collection In The American West, and held an exhibition in the same year.

In Richard Avedon's photos, the portraits of "common people in the west" became more depressed and alienated than previous portraits he shot. He tried to show the sunken culture mode of the American West by narrating the humble work of people. Under this culture mode, there would be a lot of inappropriate people, the homeless, the degraded, funny people, instigator, etc. They became the victims of the society. These people were "hostages" of him to accuse the society, and his thoughts were expressed by the people standing in front of his camera (Fig.10).

\footnotetext{
${ }^{10}$ American photographer
} 


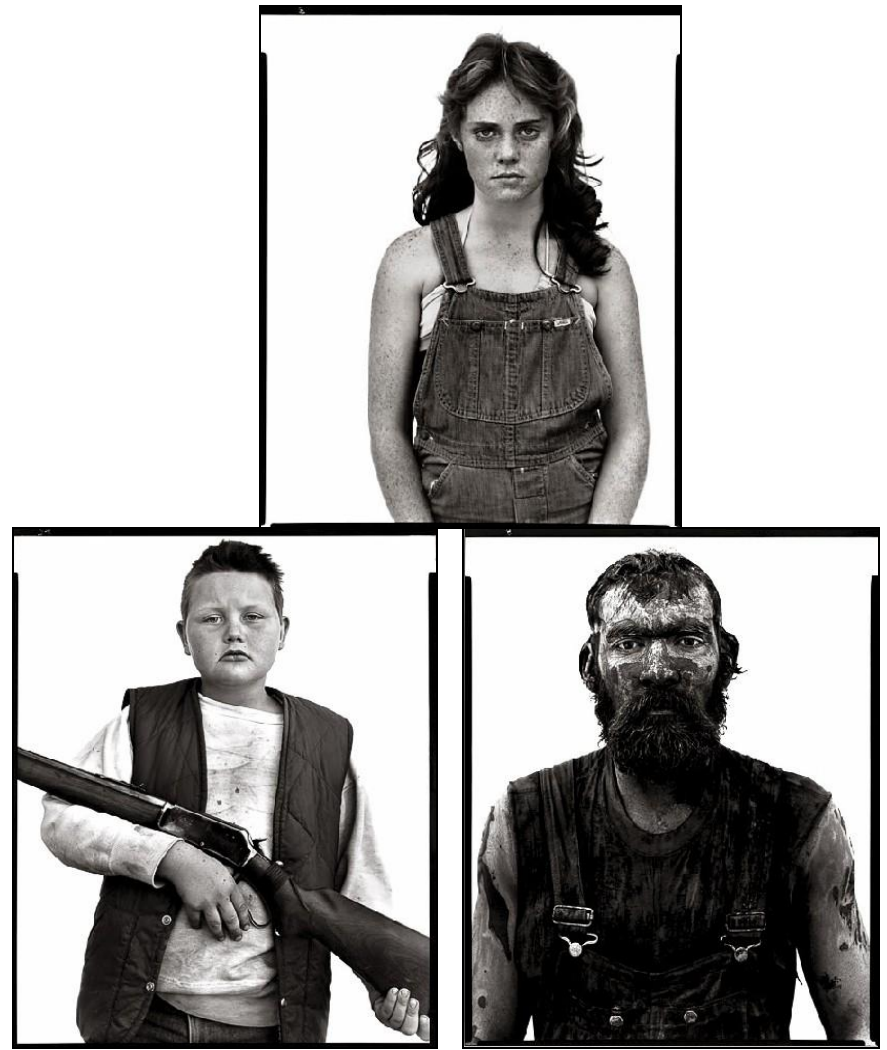

Fig. 10. Richard Avedon's In The American West from 1979 to 1984

These figures were placed before the pale seamless background cloth by Richard Avedon, and were directly or even "cruelly" compressed by large-format camera" from the front in a wanted photo mode. They are shaped clearly and vividly, just like fashion. In these works, readers cannot find any clues or related environment, because Richard didn't use any elements that can set off or support the real world of these figures (Fig.11).

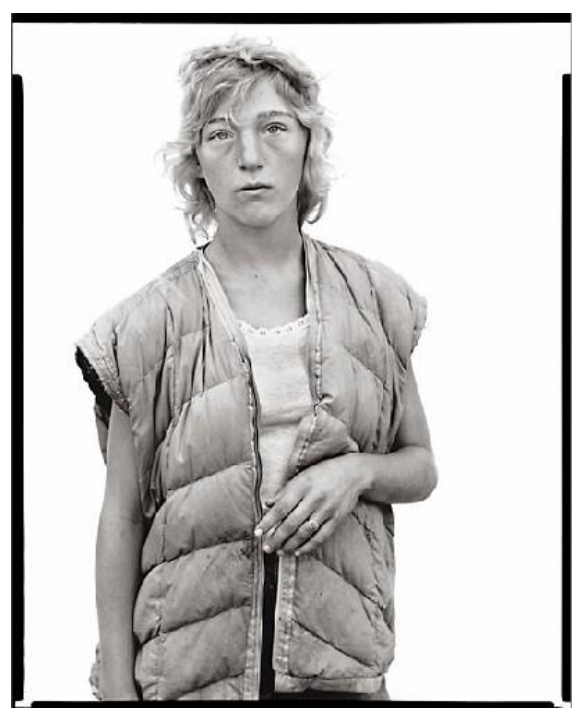

Fig. 11. Richard Avedon's In The American West from 1979 to 1984

\footnotetext{
${ }^{11}$ Here it refers to Richard Avedon's 8 x 10 camera.
}

However, Readers could clearly see the frustration and suffering of these people from these photos. The unsatisfactory work and unemployment states were clearly caught by Richard Avedon's camera. These "proletariats" shape a strong contrast with the "propertied men" Richard Avedon previously shot. For him, celebrity and upper class were of same material, while the miserable people in society were of another material.

At the end of In The American West, Richard Avedon once again stressed the theme he wanted to express with the method same as that of Portraits. He displayed a series of photos, like the clear or dim eyes of flocks and herds, blood-stained grimy furs and heads dripping with blood, by shooting the scene of slaughtering flocks and herds. Just like his father Jacob was the only "non-celebrity" in Portraits. In In The American West, the "non-human" animals play a similar role, as if it proves that Richard Avedon, at any time, wanted to break the species boundaries and stressed the philosophies he received.

In the same year of the publishing of In The American West, the photography exhibition ${ }^{12}$ of In The American West also made a great success. Richard Avedon selected more than 100 photos from the 725 portrait photos shot with his costly largeformat plenoptic camera of good optical imaging. He enlarged them into $4 \times 5$ huge photos and mount with expensive metal frame. These photos, like more than 100 big question marks and exclamations, showed the dull, confused, dejected and angry expressions of the people in America Society, which broke the Western myth made by Hollywood. It caused a strong sensation in American society.

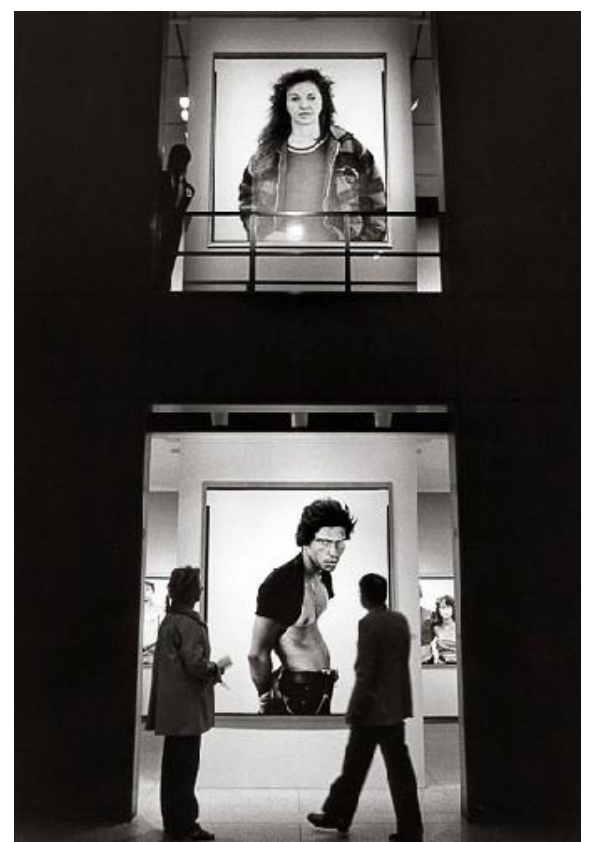

Fig. 12. The exhibition site of In The American West

\footnotetext{
12 at Amon Carter Museum in 1985.
} 


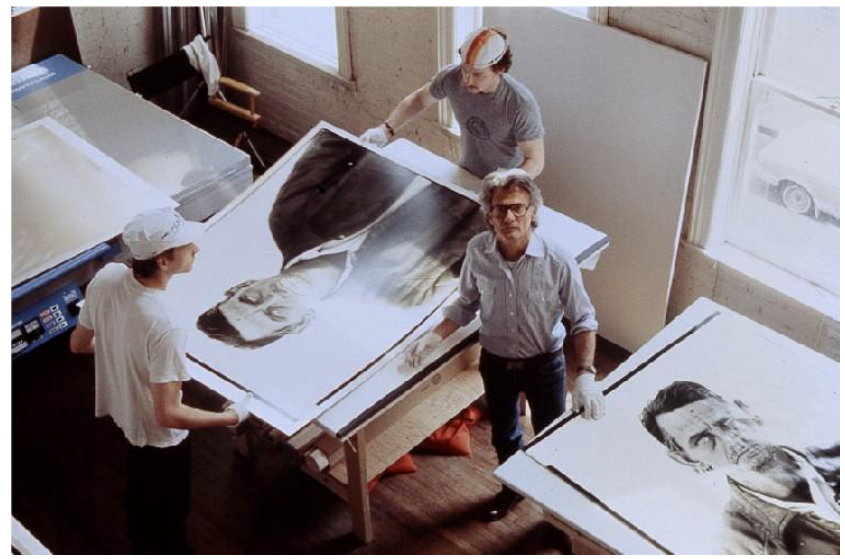

Fig. 13. Richard Avedon was mounting the exhibition photos of In The American West.

In The American West is undoubtedly a magnum opus of Richard Avedon. However, when Richard Avedon published these photographs, he wrote "when a fact is transformed into a photograph, it is no longer a fact but an opinion. In it, there is no right or wrong. All photos are accurate, but no one is a fact". It completely negates the shooting way of In The American West.

\section{CONCLUSION}

The famous photographer Richard Avedon, full of wisdom and varied in style, always changed his shooting styles in his lifelong photography career. He was always concerned about the society, and he spared no efforts to show us the "suffering" behind fashion - "universal suffering of mankind"...

\section{REFERENCES}

[1] Jia Tao. Aesthetics. Beijing: China Environmental Science Press. 2006: $264 \sim 265$.

[2] Gu Zheng. When Panic Comes - Confessions of World Contemporary Photographers II. Shanghai: Shanghai Literature and Art Publishing House. 2009: 89 97.

[3] ICP Encyclopedia of Photography. Translated by Wang Jingtang et al. Beijing: China Photography Publishing House. 1992: 61 62.

[4] Sun Jingtao. Eyes of Times. Artistic Comments of 15 Master Photographers. Beijing: China Workers Publishing House. 2008: 24 42. 